\title{
SIMULTANEOUS DETERMINATION OF 2-CHLORO METHYL PROPIONATE, 1,4-DI-BROMO BUTANE AND PARA ANISIC ALDEHYDE IN MEBEVERINE HYDROCHLORIDE API BY GAS CHROMATOGRAPHY-MASS SPECTROMETRIC WITH SELECTED-ION-MONITORING MODE
}

\author{
MANNEM DURGA BABU ${ }^{1}$, SURENDRABABU $\mathrm{K}^{1 *}$, UMA MAHESWAR K ${ }^{2}$
}

${ }^{1}$ Department of Chemistry, ANU Research Centre, SVRM PG College, Nagaram, Guntur, Andhra Pradesh, India. ${ }^{2}$ Department of Chemistry, KVR,KVR and MKR College, Khajipalem, Andhra Pradesh, India. Email: m.durgababu1989@gmail.com

Received: 11 June 2016, Revised and Accepted: 23 June 2016

\section{ABSTRACT}

Objective: To develop an accurate, precise and linear gas chromatography-mass spectrometric (GC-MS) selected-ion-monitoring (SIM) method for quantitative estimation of 2-chloro methyl propionate (2-CMP), 1,4-dibromo butane and para anisic aldehyde (PAA) as an genotoxic impurities in mebeverine $\mathrm{HCl}$ API (MEB) at ppm level and validated as per International Council of Harmonization (ICH) guidelines.

Methods: This method used in SIM mode mass selective detection was developed and validated for the trace level analysis of three impurities. All these three impurities are simultaneously determined by a GC-MS method using VF-624 Capillary column $(60 \mathrm{~m} \times 0.32 \mathrm{~mm} \times 1.80 \mu \mathrm{m}) \mathrm{with} \mathrm{Helium}$ as carrier gas and a flow rate of $2.0 \mathrm{~mL} /$ minutes. Chromatographic separation of 2-CMP, 1,4-DBB, and PAA was achieved in 7.91, $13.69,18.45$ minutes and $\mathrm{m} / \mathrm{z}$ values were $63,55,135$ on SIM mode.

Results: The method was linear for 2-CMP, 1,4-DBB and PAA in mebeverine $\mathrm{HCl} 1.90 \mu \mathrm{g} / \mathrm{ml}$ to $7.5 \mu \mathrm{g} / \mathrm{ml}$, respectively. The coefficient of correlation $\left(\mathrm{r}^{2}\right)$ for the 2-CMP, 1,4-DBB and PAA was better than 0.999. The limit of detection obtained was $0.28,0.35,0.22 \mu \mathrm{g} / \mathrm{ml}$ and the limit of quantification (LOQ) obtained was $0.85,1.06,0.66 \mu \mathrm{g} / \mathrm{ml}$. The method was fully validated, complying Food and Drug Administration, ICH and European Medicines Agency guidelines. Furthermore, verified precision, accuracy, LOQ precision, LOQ accuracy, ruggedness, and robustness.

Conclusion: The proposed method is specific, accurate, precise, linear, rugged and robust for the determination of the three genotoxic impurities in API of mebeverine $\mathrm{HCl}$, and hence, is of wide applicability in pharmaceutical industries.

Keywords: 2-chloro methyl propionate, 1,4-dibromo butane, Para anisic aldehyde, Mebeverine $\mathrm{HCl}$, Gas chromatography-mass spectrometric, Method development, Method validation.

(C) 2016 The Authors. Published by Innovare Academic Sciences Pvt Ltd. This is an open access article under the CC BY license (http://creativecommons. org/licenses/by/4. 0/) DOI: http://dx.doi.org/10.22159/ajpcr.2016.v9s2.13418

\section{INTRODUCTION}

Mebeverine $\mathrm{HCl}$ (Fig. 1) is an antimuscarinic. The IUPAC name was 4-[ethyl-[1-(4-methoxyphenyl) propan-2-yl] amino] butyl 3,4-dimethoxybenzoate; hydrochloride with molecular formula $\mathrm{C}_{25} \mathrm{H}_{36} \mathrm{ClNO}_{5}$. It belongs to a group of compounds called musculotropic antispasmodics. These compounds act directly on the gut muscles at the cellular level to relax them. This relieves painful muscle spasms of the gut without affecting its normal motility. Mebeverine is used to relieve symptoms of irritable bowel syndrome and related intestinal disorders that are the result of spasms in the intestinal muscles. These include colicky abdominal pain and cramps, diarrhea alternating with constipation and flatulence. Mebeverine is also an inhibitor of calciumdepot replenishment. Therefore, it has a dual mode of action which normalizes the small bowel motility. It was first registered in 1965 and is marketed as Colofac, Duspatal, Colotal, Colospa, Mebeverine, Rudakol, Boots IBS relieve, Fomac, Mebecon and Duspatalin by Abbott Laboratories. British Pharmacopoeia described a non-aqueous titrimetric method for determination of MEB in the pure form [1,2].

According to current regulatory guidelines, it is important that the genotoxic impurities potentially damage the DNA at very low-level exposure. Genotoxic substances are the chemicals that harm an organism by damaging its genetic material. There are three primary effects that genotoxins can have on organisms by effecting their genetic information. Genotoxins can be carcinogens or mutagens or teratogens. Potential impurities most likely arise during synthesis, purification, and storage should be identified. As per USFDA guidelines regarding the limits of genotoxic impurities, a maximum of $1.5 \mu \mathrm{g}$ per a day is the exposure limit $[3,4]$.
Three genotoxic impurities, 2-chloro methyl propionate (2-CMP), 1,4-dibromo butane (1,4-DBB), and para anisic aldehyde (PAA) (Fig. 2) may present in the API of mebeverine $\mathrm{HCl}$. An approach based on GC-MS is feasible within limits of time, ease of application, sensitivity, and cost. Despite the importance of the issue, no method is so far reported for the simultaneous determination of these impurities in API of mebeverine $\mathrm{HCl}[5,6]$.

\section{METHODS}

\section{Chemicals and reagents}

2-CMP, 1, 4-DBB and PAA were purchased from Sigma-Aldrich. Mebeverine hydrochloride was purchased from a local research laboratory. High-performance liquid chromatography grade ethyl acetate was purchased from MERCK. Water was purified by a Millipore- $Q$ academic water purification system. All other chemicals and reagents used for the experiments were of analytical grade.

\section{Instrumentations and conditions}

The system consists of an GC-MS-QP 2010 plus (Shimadzu) with electron ionization probe. System control and data analysis were processed with GC-MS solutions software. Chromatography was perfumed on a VF-624 ms capillary column $(60 \mathrm{~m} \times 0.32 \mathrm{~mm} \times 1.80 \mu \mathrm{m})$.

The GC oven temperature program utilized an initial temperature of $100^{\circ} \mathrm{C}$ and an initial holding time of 5.0 minutes, and then increased at $20^{\circ} \mathrm{C} /$ minutes to $200^{\circ} \mathrm{C}$. The final temperature was held for 10.0 minutes. The injection temperature is $225^{\circ} \mathrm{C}$. Helium gas was used as the carrier gas with a flow rate of $2.0 \mathrm{ml} /$ minute and purge flow is $1.0 \mathrm{ml} /$ minute. An injection volume with $1.0 \mu \mathrm{l}$. 


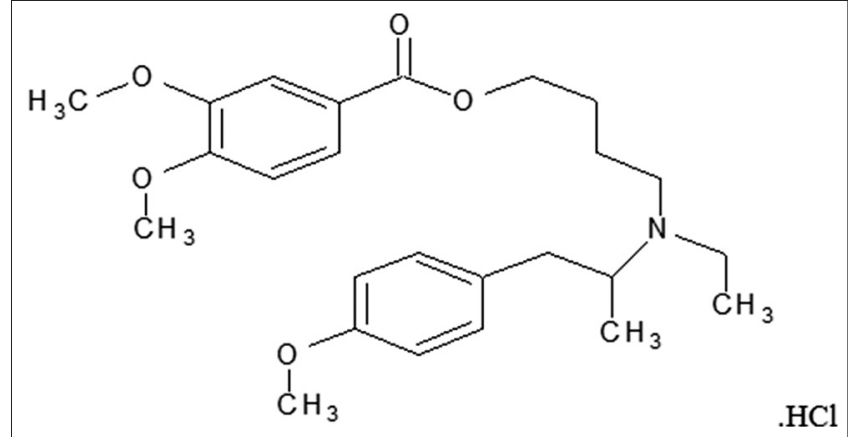

Fig. 1: Structure of mebeverine hydrochloride

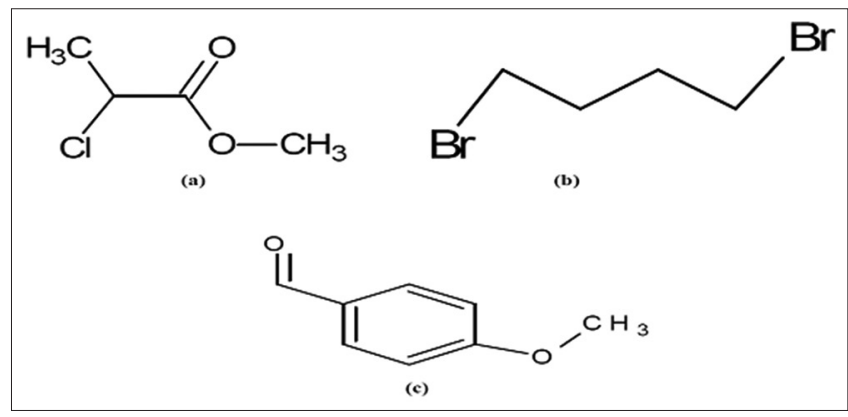

Fig. 2: Structure of (a) 2-chloro methyl propionate,

(b) 1,4-dibromo butane, (c) Para anisic aldehyde

Selected-ion-monitoring (SIM) at unit resolution was employed to monitor the transitions of the prorogated forms of 2-CMP at $\mathrm{m} / \mathrm{z} 63$, 1, 4-DBB at $\mathrm{m} / \mathrm{z} 55$ and PAA at m/z 135 in the SIM mode. Optimized MS conditions were described as follows: GC-MS interface temperature with $250^{\circ} \mathrm{C}$, ion source temperature is $260^{\circ} \mathrm{C}$, solvent cut time with 6.0 minutes, detector voltage with $0.92 \mathrm{kv}$.

\section{Preparation of solutions}

\section{Preparation of sample solution}

Ethyl acetate was used as the diluent for the standard and sample solution preparation. Mebeverine $\mathrm{HCl}$ sample was prepared by weighing $10.0 \pm 0.005 \mathrm{~g}$ into a $20 \mathrm{ml}$ volumetric flask and diluted to volume with diluents at a concentration of approximately $400 \mathrm{mg} / \mathrm{ml}$. Sonicate for 10 minutes. Then filter this solution, filtrate was used for the analysis.

\section{Preparation of standard solution}

2-CMP, 1,4-DBB and PAA reference standard stock solution were prepared in diluent at a concentration of approximately $4.0 \mu \mathrm{g} / \mathrm{ml}$ each. The working standard solution of 2-CMP, 1,4-DBB and PAA were prepared by pipetting $0.75 \mathrm{ml}$ from standard stock solution into $50 \mathrm{ml}$ volumetric flask and diluted to volume with diluent at a concentration of approximately $1.5 \mu \mathrm{g} / \mathrm{ml}$. The above Standard stock and working solution were stored at room temperature until use. The standard solution of each genotoxic impurity was prepared at $3.75 \mu \mathrm{g} / \mathrm{ml}$ with respect to sample concentration $(400 \mathrm{mg} / \mathrm{ml})$.

\section{RESULTS AND DISCUSSION}

\section{Method development}

This method development was implemented following Quality-byDesign principles including diluent selection, column screening, and column temperature determination. Method development samples were prepared using each of individual reference standard of mebeverine $\mathrm{HCl}$, 2-CMP, 1,4-DBB and PAA.

\section{Diluent selection}

This method development was started with the selection of diluent that was suitable for dissolving 2-CMP, 1,4-DBB and PAA, but mebeverine
$\mathrm{HCl}$ should not be dissolved. Because the sample solution is not passes through the mass ion source, 2-CMP, 1,4-DBB and PAA are soluble in methanol, ethyl acetate, and ethanol. While sample was in-soluble in ethyl acetate. Therefore, the diluent for 2-CMP, 1,4-DBB and PAA should be ethyl acetate.

\section{Column screening}

Column selection for chromatographic analysis was also an important step in method development. This study utilized a chromatographic basic rule "like attracts like" and focused on the polarity matching among column Stationary Phase and Mobile Phase. In this study, three columns, namely, VF-1 ms $(30 \mathrm{~m} \times 0.32 \mathrm{~mm} \times 0.45 \mu \mathrm{m}), \mathrm{VF}-624 \mathrm{~ms}$ ( $60 \mathrm{~m} \times 0.32 \mathrm{~mm} \times 1.8 \mu \mathrm{m})$, and ZB-5 $\mathrm{ms}(30 \mathrm{~m} \times 0.25 \mathrm{~mm} \times 0.25 \mu \mathrm{m})$ for evaluated for column screening. The chromatographic parameters were first optimized to achieve good retention, high resolution and better peak shapes for the 2-CMP, 1,4-DBB and PAA in mebeverine $\mathrm{HCl}$.

In the method development experiment, The VF-624 ms eluted three sharp peaks with minimal peak tailing for 2-CMP at retention time about 7.91 minutes, 1,4-DBB at about 13.69 minutes and PAA at about 18.45 minutes. It demonstrated that VF-624 column closely matched the 2-CMP, 1,4-DBB and PAA. The chromatogram obtained from the VF$624 \mathrm{~ms}$ column screening preliminarily concluded that this column was appropriate and meet the method requirement.

However, an additional column screening was continued for the purpose of developing more useful methods for future troubleshooting. The second column evaluated was the VF-1 ms ( $30 \mathrm{~m} \times 0.32 \mathrm{~mm} \times 0.45 \mu \mathrm{m}$ ). In this study, the VF-1 ms column could separate 2-CMP, 1,4-DBB and PAA with good peak symmetry. However, peak area was decreased by $30 \%$, possibly due to the difference of particle sizes. Therefore, VF-1 ms column was not matched to these three genotoxic impurities.

The third column studied was ZB- $5 \mathrm{~ms}(30 \mathrm{~m} \times 0.25 \mathrm{~mm} \times 0.25 \mu \mathrm{m})$ column. In this study, the ZB- 5 ms column could not separate the peeks of 2-CMP, 1,4-DBB and PAA. Therefore, ZB-5 ms column was also not matched to these three genotoxic impurities.

Based on the above optimized methods for column screening, the results proved that the VF- $624 \mathrm{~ms}(60 \mathrm{~m} \times 0.32 \mathrm{~mm} \times 1.8 \mu \mathrm{m})$ column afforded the best retention and separation of all three genotoxic impurities in mebeverine $\mathrm{HCl}$. Hence, the VF-624 ms column was selected for further study.

\section{Column temperature determination}

Two column temperatures were evaluated during method development, namely, initial was same as $100^{\circ} \mathrm{C}$, and final temperature is $200^{\circ} \mathrm{C}$ and $250^{\circ} \mathrm{C}$. The determination was carried out based on a visual check of chromatogram and comparison of peak areas. In general, higher temperature has proven effective for improving the overall chromatographic performance, but the column temperature of $250^{\circ} \mathrm{C}$ eluted components faster and decreased the resolution of three impurity peaks in mebeverine $\mathrm{HCl}$. When using the $200^{\circ} \mathrm{C}$ temperature, the peak separation is good and resolution is good. Hence, the column temperature of $200^{\circ} \mathrm{C}$ was determined for further study.

\section{Mass spectral analysis}

Based on the retention time obtained from the standard injection, solvent cut time and MS acquisition time were decided. As per the analysis conducted by GC-MS and the retention time of 2-CMP, 1, 4-DBB and PAA was in between 7.0 to 8.0 minutes, 13.0 to 14.0 minutes and 18.0 to 19.0 minutes, respectively. Hence, the solvent cut time was kept at 0.0 to 6.0 minutes. The three compounds were identified using the reference spectra (NIST) and $\mathrm{m} / \mathrm{z}$ values for the SIM mode were finalized as 63 for 2-CMP, 55 for 1,4-DBB and 135 for PAA. The spectrum of the analytes, 2-CMP, 1,4-DBB and PAA, match to the reference spectra of NIST. The mass chromatogram and mass spectra of 2-CMP, 1,4-DBB and PAA are shown in Fig. 3. 


\section{Method validation}

The proposed method was validated for specificity, linearity, accuracy, precision, limit of detection (LOD) and limit of quantification (LOQ), LOQ precision and accuracy, ruggedness and robustness as per International Council of Harmonization method validated guidelines [7-9].

\section{Specificity}

The mebeverine $\mathrm{HCl}$ API sample was spiked with 2-CMP, 1,4-DBB and $\mathrm{PAA}$, and sample was chromatographed to examine interference of any of the genotoxic impurity peaks with each other. The retention time for standard 2-CMP is 7.91 minutes, 1,4-DBB is 13.69 minutes, and PAA is 18.45 minutes. The chromatograms are shown in Fig. 4.

\section{Repeatability}

The precision of the method was evaluated at a single level. Repeatability was checked by calculating the percentage of relative standard deviation (\%RSD) of six replicate determinations by injecting six freshly prepared solutions containing $1.5 \mu \mathrm{g} / \mathrm{ml}$ each of the mixture of impurities on the same day. As reported in Table 1, \%RSD values were lower than 10.0\% for the three impurities. This is confirmed an adequate precision of the developed method. The \%RSD chromatograms of three impurities are shown in Fig. 5.

\section{Linearity}

The linearity of 2-CMP, 1,4-DBB and PAA genotoxic impurities were satisfactorily demonstrated with a five-point calibration graph

a
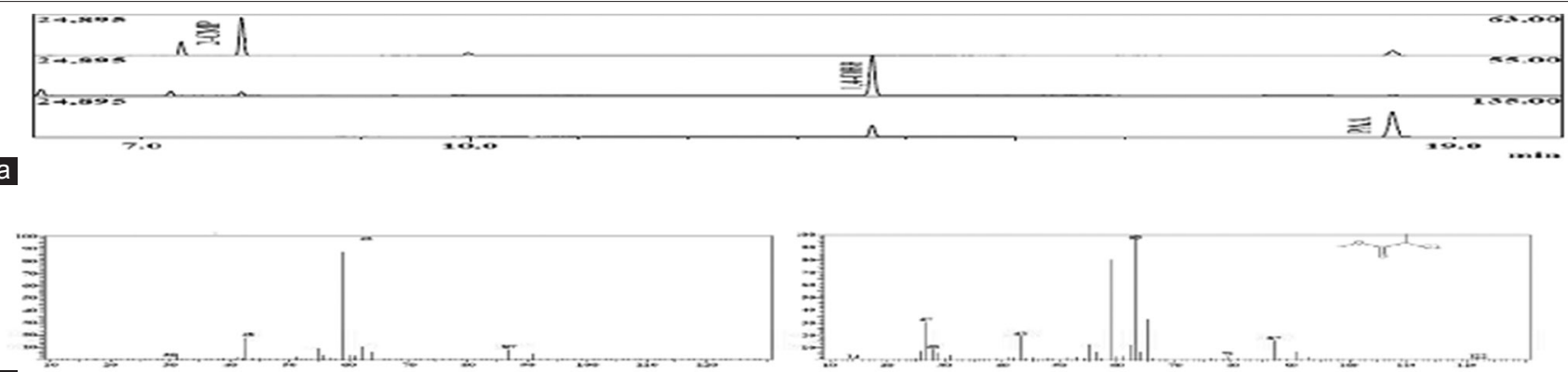

b
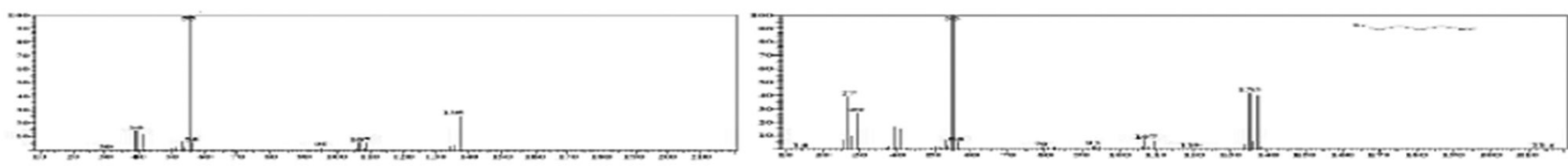

c
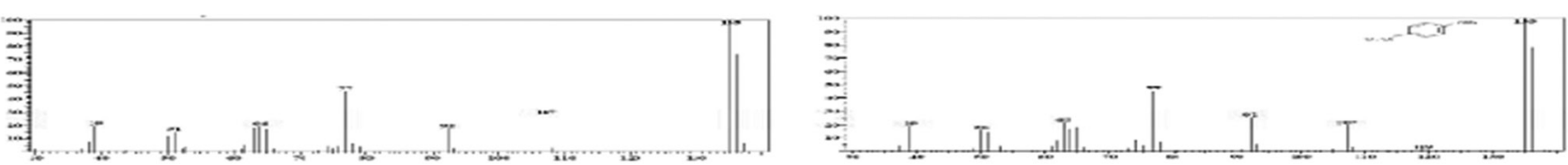

d

Fig. 3: (a) Mass chromatogram in SIM mode, (b-d) mass spectrums and reference mass spectrums (NIST) of 2-chloro methyl propionate, 1,4-dibromo butane and para anisic aldehyde

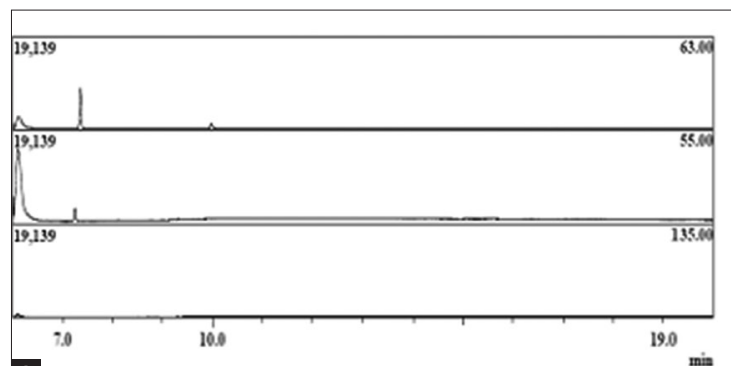

a
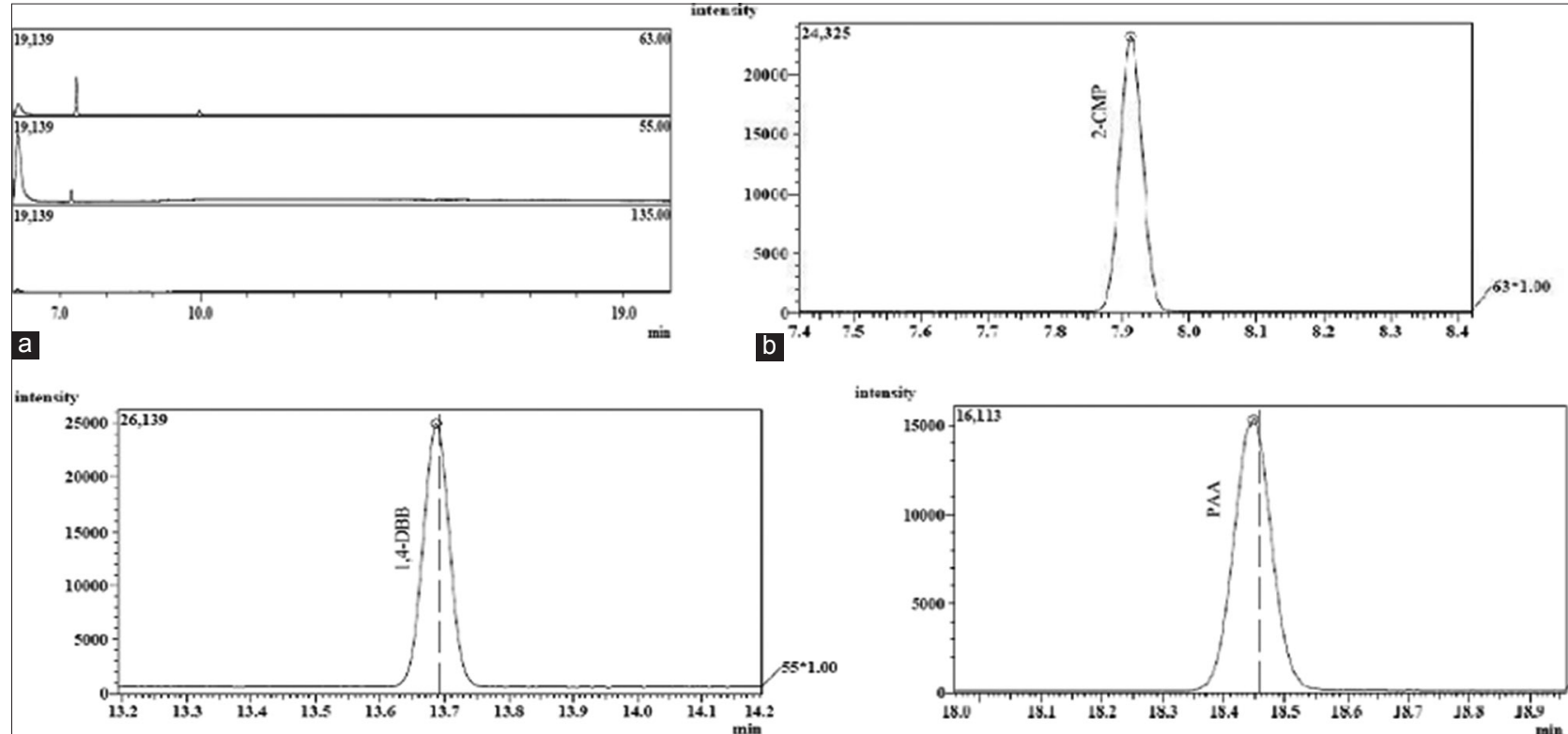

C

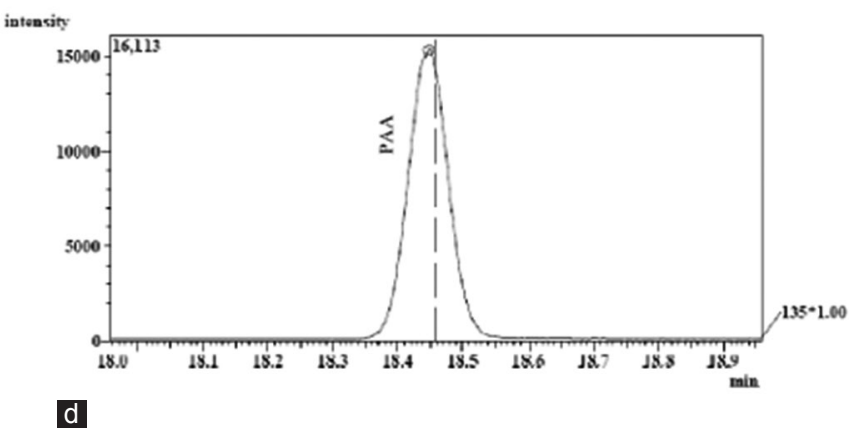

Fig. 4: Specificity chromatograms of (a) blank, (b) 2-chloro methyl propionate, (c) 1,4-dibromo butane, (d) para anisic aldehyde 
Table 1: Repeatability data for 2-CMP, 1,4-DBB and PAA

\begin{tabular}{llll}
\hline Serial number & 2-CMP & 1,4-DBB & PAA \\
\hline 1 & 47996 & 5885 & 54733 \\
2 & 47887 & 59321 & 54660 \\
3 & 46185 & 58268 & 54906 \\
4 & 49822 & 62922 & 56880 \\
5 & 49488 & 62414 & 57709 \\
6 & 49594 & 62860 & 58227 \\
Average area & 48495 & 60945 & 56186 \\
Standard deviation & 1408 & 2033 & 1615 \\
\% of RSD & 2.90 & 3.34 & 2.87 \\
\hline 2-CMP: 2-chloro methyl propionate, 1,4-DBB: 1,4-dibromo butane, PAA: Para \\
anisic aldehyde, RSD: Relative standard deviation
\end{tabular}

between 1.9 and $7.5 \mu \mathrm{g} / \mathrm{ml}$ with respect to a sample concentration of $400 \mathrm{mg} \mathrm{ml}$. The calibration curves were produced by plotting the average of triplicate genotoxic impurities injections against the concentration expressed in $\mu \mathrm{g} / \mathrm{ml}$. The slope, intercept, and correlation coefficient values were derived from linear least squares regression analysis. The correlation coefficient obtained in each case was $>0.99$. The corresponding linearity data and graphs are presented in Table 2 and Fig. 6 . The results indicated that an excellent correlation existed between the peak areas and the concentrations of impurities.

\section{Accuracy}

Weighed accurately $10.0 \mathrm{~g}$ of the mebeverine $\mathrm{HCl}$ API into three different $25 \mathrm{ml}$ of volumetric flasks and spiked with 50\%, 100\% and

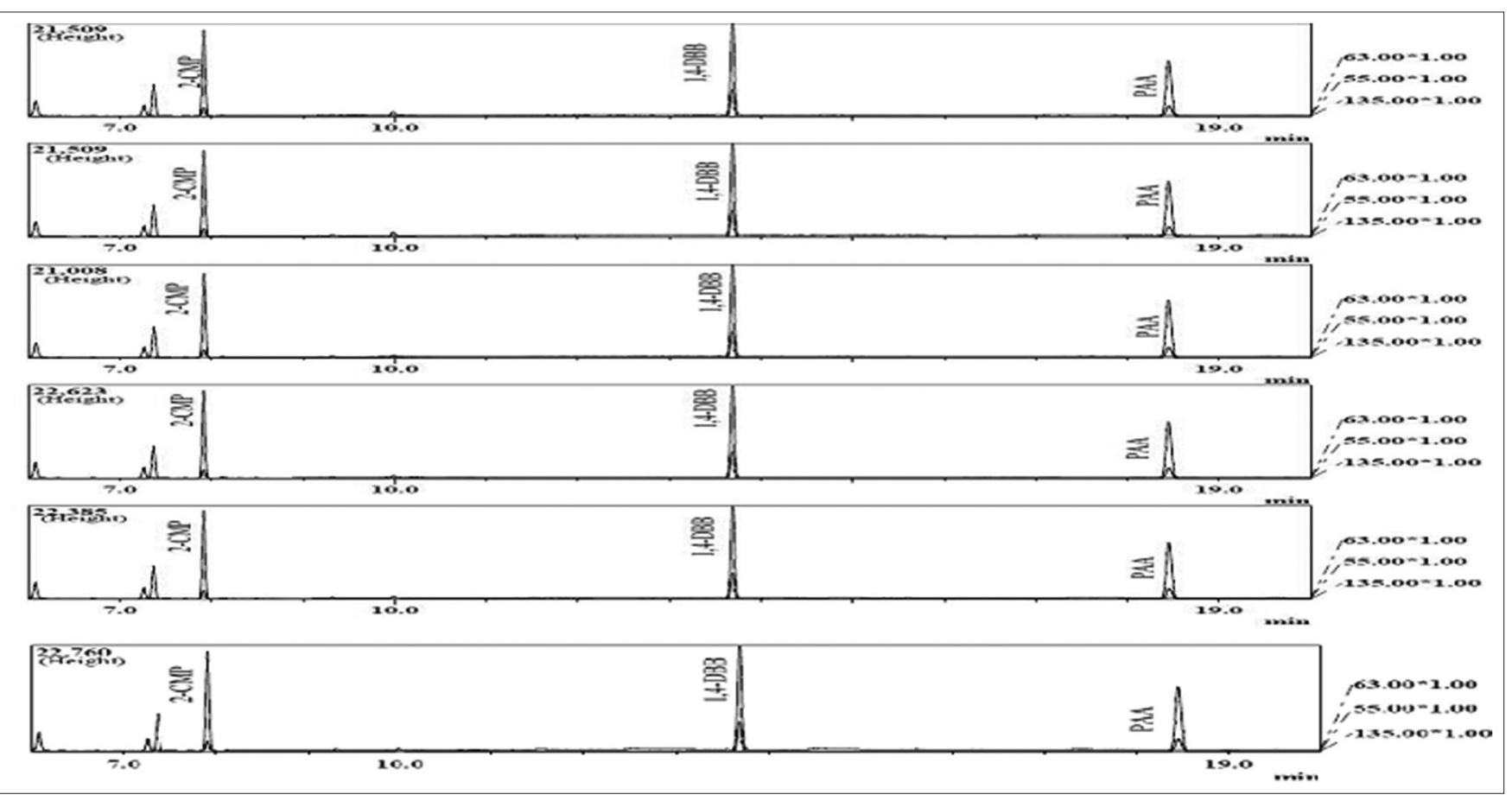

Fig. 5: Typical \% relative standard deviation chromatogram of precision for 2-chloro methyl propionate, 1,4-dibromo butane and para anisic aldehyde

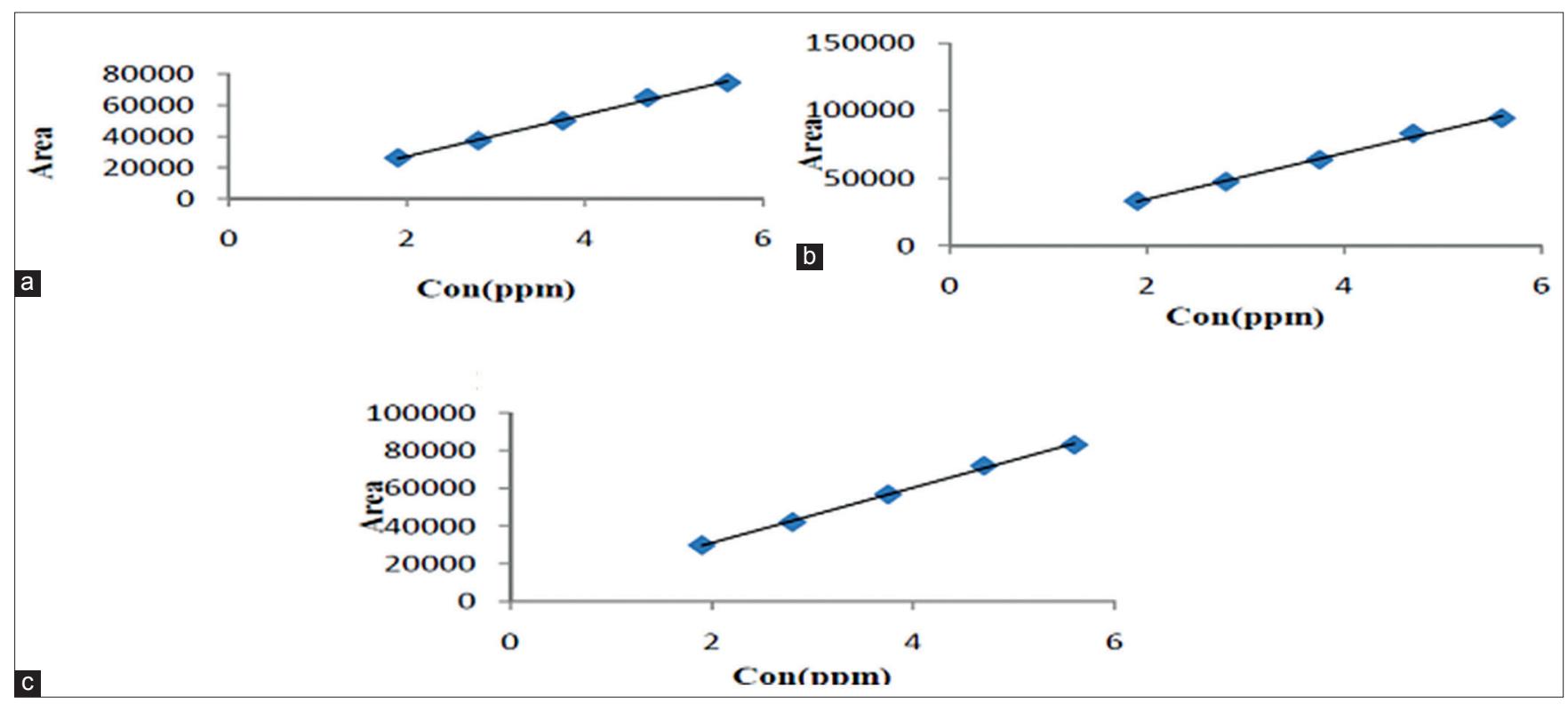

Fig. 6: Linearity graphs for (a) 2-chloro methyl propionate, (b) 1,4-dibromo butane and, (c) para anisic aldehyde 
$150 \%$ standard solutions of 2-CMP, 1,4-DBB and PAA. Added $20 \mathrm{ml}$ of diluents, mixed well then made up with the same diluents, then filtered and the filtrate was used for injection. Standards of the three impurities and three spiked samples at 50\%, 100\% and 150\% levels in triplicate are injected. From accuracy data, the \% recovery of 2-CMP, 1, 4-DBB and PAA was found within the limits $(100 \pm 15 \%)$. The results indicate that the method has an acceptable level of accuracy. The recovery data is presented in Table 3 .

\section{LOD and LOQ}

The LOD and LOQ were calculated by instrumental and statistical methods. For the instrumental method, LOD is determined as the lowest amount to detect, and LOQ is the lowest amount to quantify, by the detector. Further LOD and LOQ values were established using calibration curve method. Standard solutions ranging from 1.9 to $7.5 \mu \mathrm{g} / \mathrm{ml}$ for three analytes were injected into the system for performing LOD and LOQ prediction study. Based on the concentrations obtained from slope and intercept of the prediction activity, LOD and LOQ precision activity performed. LOD values for 2-CMP, 1,4- DBB and PAA were 0.28, 0.35 and $0.22 \mu \mathrm{g} / \mathrm{ml}$, respectively. LOQ values for 2-CMP, 1, 4-DBB and PAA were $0.85,1.06$, and $0.66 \mu \mathrm{g} / \mathrm{ml}$, respectively. Prepare the standard three impurities 2-CMP, 1, 4-DBB and PAA solutions at LOD and LOQ concentrations. The corresponding linearity data graphs at LOD and LOQ concentration are presented in Table 4 and Figs. 7 and 8

\section{LOQ precision}

Prepare the standard 2-CMP, 1,4-DBB and PAA solutions at LOQ concentration $(0.85,1.06$ and $0.66 \mu \mathrm{g} / \mathrm{ml})$ and injected in six replicates. The $\% \mathrm{RSD}(\mathrm{n}=6)$ values obtained for the average area of 2-CMP, 1,4- DBB and PAA are 21238, 27371 and 27938 . The acceptance criteria of \%RSD for Three impurities are not more than 10\%. The LOQ precision data and chromatograms of LOD and LOQ are shown in Table 5 and Fig. 9

\section{LOQ accuracy}

Weighed accurately $10.0 \mathrm{~g}$ of the Mebeverine HCl API into three different $25 \mathrm{ml}$ of volumetric flasks and spiked with LOQ level three standard solutions of 2-CMP, 1, 4-DBB and PAA, add $10 \mathrm{ml}$ of diluents mix well then makeup with the same diluents. Filter the solution take the filtrate for injection. Then, inject in triplicate. From accuracy data at LOQ level, the $\%$ recovery of 2-CMP, 1,4-DBB and PAA were found within the limits $(100 \% \pm 15 \%)$. The results are presented in Table 6 .

\section{Ruggedness}

The ruggedness of the method was evaluated by performing the sample analysis in six replicates using different analyst on different days, and
Table 2: Linearity data for 2-CMP, 1,4-DBB and PAA

\begin{tabular}{llll}
\hline $\begin{array}{l}\text { Concentration } \\
(\boldsymbol{\mu} \mathbf{g} / \mathbf{m l})\end{array}$ & Area of 2-CMP & Area of 1,4-DBB & Area of PAA \\
\hline 1.9 & 26219 & 33046 & 29876 \\
2.8 & 37286 & 47371 & 42078 \\
3.75 & 50018 & 63675 & 56753 \\
5.6 & 64869 & 83143 & 71923 \\
7.5 & 74580 & 94506 & 83057 \\
Correlation & 0.999 & 0.999 & 0.998 \\
coefficient $\left(\mathrm{r}^{2}\right)$ & & & \\
\hline
\end{tabular}

2-CMP: 2-chloro methyl propionate, 1,4-DBB: 1,4-dibromo butane, PAA: Para anisic aldehyde

Table 3: Accuracy data for 2-CMP, 1,4-DBB and PAA

\begin{tabular}{llll}
\hline \% Accuracy & $\begin{array}{l}\text { Average area } \\
\text { of 2-CMP }\end{array}$ & $\begin{array}{l}\text { Average area } \\
\text { of 1,4-DBB }\end{array}$ & $\begin{array}{l}\text { Average } \\
\text { area of PAA }\end{array}$ \\
\hline STD solution $(\mathrm{n}=3)$ & 63988 & 88605 & 74394 \\
$50 \%$ level $(\mathrm{n}=3)$ & 33828 & 45931 & 35231 \\
\% of recovery & 105.73 & 103.67 & 94.71 \\
100 \% level (n=3) & 69114 & 92299 & 80861 \\
\% of recovery & 108.01 & 104.17 & 108.69 \\
150 \% level (n=3) & 91087 & 123477 & 117285 \\
$\%$ of recovery & 94.90 & 92.90 & 105.10 \\
\hline
\end{tabular}

2-CMP: 2-chloro methyl propionate, 1,4-DBB: 1,4-dibromo butane, PAA: Para anisic aldehyde

Table 4: Linearity graph data for 2-CMP, 1,4-DBB and PAA at LOQ concentration

\begin{tabular}{llll}
\hline Concentration $(\boldsymbol{\mu g} / \mathbf{m l})$ & $\begin{array}{l}\text { Area of } \\
\text { 2-CMP }\end{array}$ & $\begin{array}{l}\text { Area of } \\
\text { 1,4-DBB }\end{array}$ & $\begin{array}{l}\text { Area of } \\
\text { PAA }\end{array}$ \\
\hline 1.9 & 26219 & 33046 & 29876 \\
2.8 & 37286 & 47371 & 42078 \\
3.75 & 50018 & 63675 & 56753 \\
5.6 & 64869 & 83143 & 71923 \\
7.5 & 74580 & 94506 & 83057 \\
Correlation coefficient $\left(\mathrm{r}^{2}\right)$ & 0.993 & 0.996 & 0.992 \\
Slope & 13372 & 17073 & 14652 \\
STEYX & 1135 & 1805 & 971 \\
LOD & $0.28 \mu \mathrm{g} / \mathrm{ml}$ & $0.35 \mu \mathrm{g} / \mathrm{ml}$ & $0.22 \mu \mathrm{g} / \mathrm{ml}$ \\
LOQ & $0.85 \mu \mathrm{g} / \mathrm{ml}$ & $1.06 \mu \mathrm{g} / \mathrm{ml}$ & $0.66 \mu \mathrm{g} / \mathrm{ml}$ \\
\hline
\end{tabular}

2-CMP: 2-chloro methyl propionate, 1,4-DBB: 1,4-dibromo butane, PAA: Para anisic aldehyde, LOD: Limit of detection, LOQ: Limit of quantification

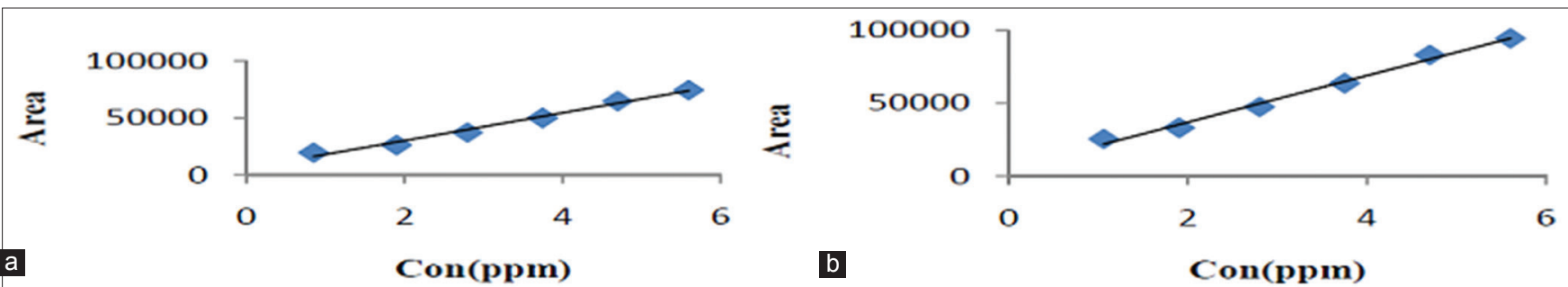

a

Con(ppm)

Con(ppm)

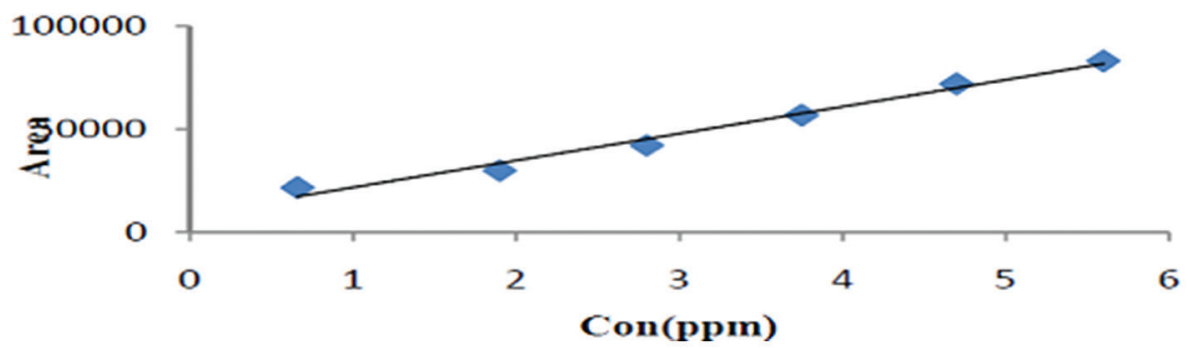

Fig. 7: Linearity graphs for (a) 2-2-chloro methyl propionate, (b)1,4-dibromo butane and (c) para anisic aldehyde at limit of quantification 


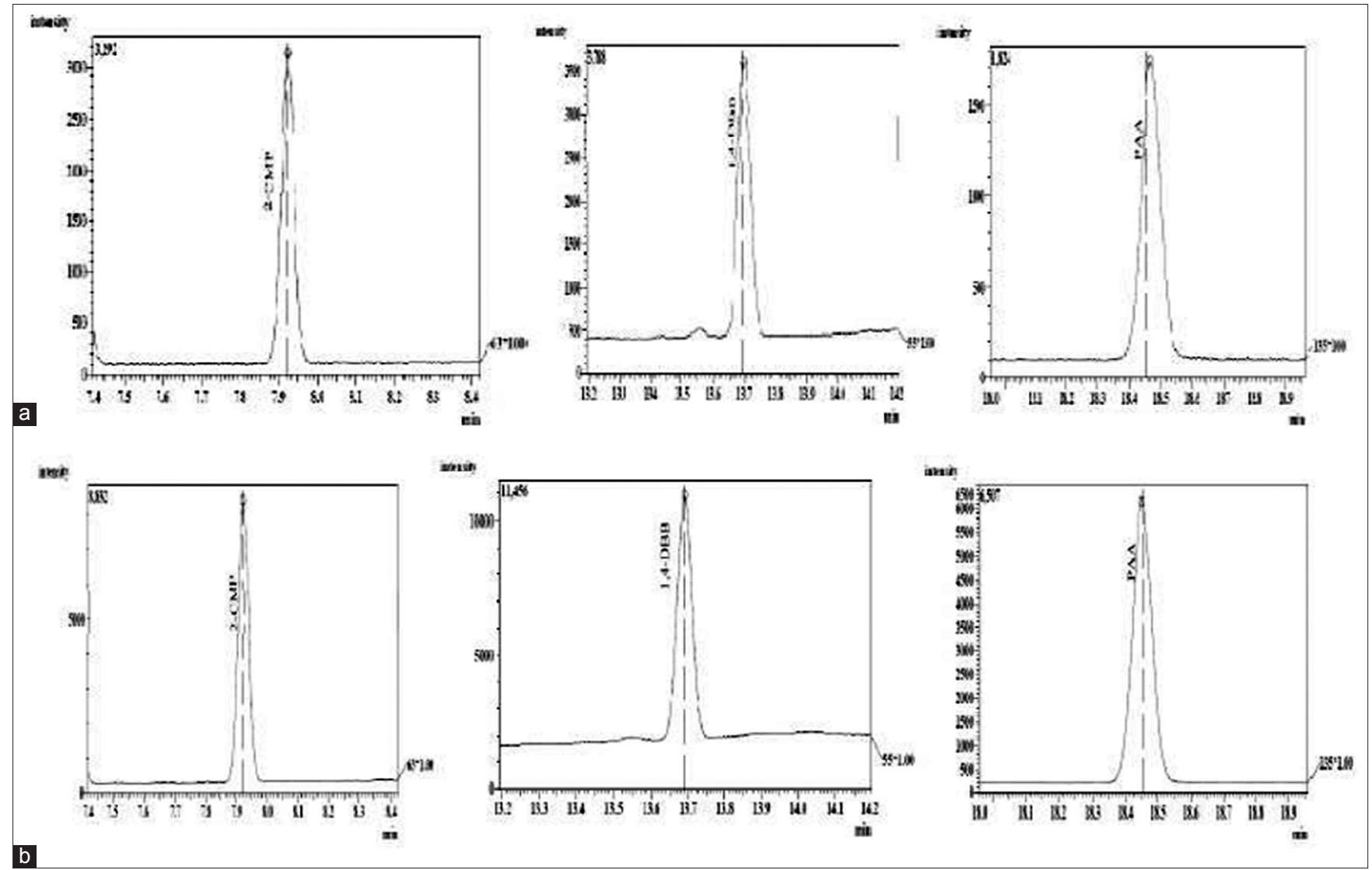

Fig. 8: (a) Limit of detection (b) limit of quantification chromatograms for 2-2-chloro methyl propionate, 1,4-dibromo butane and para anisic aldehyde

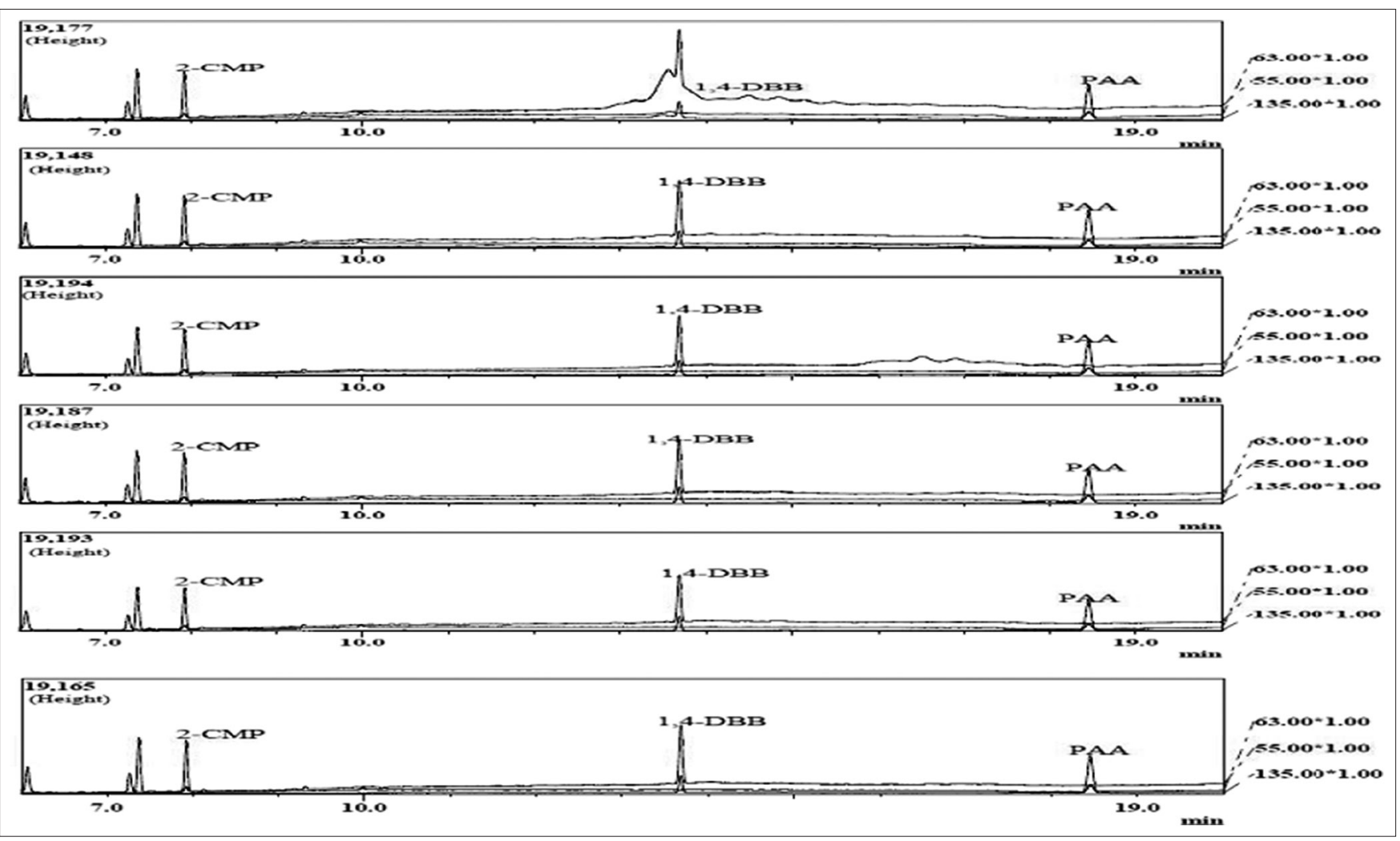

Fig. 9: Limit of quantification precision chromatograms for 2-chloro methyl propionate, 1,4-dibromo butane and para anisic aldehyde 
Table 5: LOQ precision data for 2-CMP, 1,4-DBB and PAA

\begin{tabular}{lll}
\hline Serial number & Area of 2-CMP & Area of 1,4-DBB \\
\hline 1 & 21270 & 26379 \\
2 & 22837 & 29682 \\
3 & 21054 & 27123 \\
4 & 21702 & 28564 \\
5 & 19569 & 25429 \\
6 & 20993 & 27046 \\
Average area & 21238 & 27371 \\
Standard deviation & 1063 & 1529 \\
\% of RSD & 5.01 & 5.59 \\
\hline
\end{tabular}

2-CMP: 2-chloro methyl propionate, 1,4-DBB: 1,4-dibromo butane, PAA: Para anisic aldehyde, LOD: Limit of detection, LOQ: Limit of quantification, RSD: Relative standard deviation

Table 6: LOQ-accuracy data for 2-CMP, 1,4-DBB and PAA

\begin{tabular}{lll}
\hline Accuracy \% & Average area of 2-CMP & Average area of 1,4-DBB \\
\hline Standard solution & 21238 & 27371 \\
LOQ level (n=3) & 21720 & 27693 \\
\% of recovery & 102.27 & 101.18 \\
\hline
\end{tabular}

2-CMP: 2-chloro methyl propionate, 1,4-DBB: 1,4-dibromo butane, PAA: Para anisic aldehyde, LOQ: Limit of quantification

Table 7: Ruggedness data for 2-CMP, 1,4-DBB and PAA

\begin{tabular}{|c|c|c|c|c|c|c|c|c|}
\hline \multirow{2}{*}{$\begin{array}{l}\text { Name of } \\
\text { impurity }\end{array}$} & \multicolumn{3}{|c|}{ Day 1 (RSD \% ) } & \multicolumn{3}{|c|}{ Day 2 (RSD \%) } & \multirow{2}{*}{$\frac{\text { Analyst } 1 \text { (RSD \%) }}{\text { Day } 1 \text { and } 2}$} & \multirow{2}{*}{$\begin{array}{l}\text { Analyst } 2 \text { (RSD \%) } \\
\text { Day } 1 \text { and } 2\end{array}$} \\
\hline & Analyst 1 & Analyst 2 & Analyst 1 and 2 & Analyst 1 & Analyst 2 & Analyst 1 and 2 & & \\
\hline 2-CMP & 2.78 & 2.41 & 2.48 & 2.16 & 2.25 & 2.10 & 2.56 & 2.45 \\
\hline 1,4-DBB & 2.09 & 1.92 & 1.93 & 2.80 & 2.21 & 2.44 & 2.47 & 2.30 \\
\hline PAA & 2.15 & 2.01 & 2.00 & 2.15 & 2.19 & 2.07 & 2.06 & 2.04 \\
\hline
\end{tabular}

2-CMP: 2-chloro methyl propionate, 1,4-DBB: 1,4-dibromo butane, PAA: Para anisic aldehyde, RSD: Relative standard deviation

Table 8: Robustness data for 2-CMP, 1,4-DBB and PAA

\begin{tabular}{|c|c|c|c|c|c|c|}
\hline \multirow[t]{2}{*}{ Parameter } & \multicolumn{2}{|l|}{ 2-СMP } & \multicolumn{2}{|l|}{ 1,4-DBB } & \multicolumn{2}{|l|}{ PAA } \\
\hline & Average area $(n=6)$ & RSD \% & Average area $(n=6)$ & RSD \% & Average area $(n=6)$ & RSD \% \\
\hline \multicolumn{7}{|c|}{ Flow rate $(\mathrm{ml} / \mathrm{min})$} \\
\hline 1.8 & 41431 & 2.16 & 61913 & 2.58 & 55428 & 2.22 \\
\hline 2.0 & 46001 & 2.04 & 62384 & 2.07 & 56033 & 2.24 \\
\hline 2.2 & 46547 & 2.20 & 62686 & 2.28 & 57071 & 2.10 \\
\hline \multicolumn{7}{|c|}{ Column temp $\left({ }^{\circ} \mathrm{C}\right)$} \\
\hline 195 & 45614 & 2.25 & 61201 & 2.19 & 55096 & 2.60 \\
\hline 200 & 45928 & 2.34 & 61196 & 2.83 & 55942 & 2.13 \\
\hline 205 & 46357 & 2.31 & 61961 & 2.46 & 55815 & 2.58 \\
\hline
\end{tabular}

the results are summarized as shown in Table 7 . The $\%$ RSD values of less than $10.0 \%$ for 2-CMP, 1, 4-DBB and PAA content indicate that the method adopted is rugged.

\section{Robustness}

The robustness of the method was examined by replicate injections $(\mathrm{n}=6)$ of $1.5 \mu \mathrm{g} / \mathrm{ml}$ of three standard solutions with slight modifications on the chromatographic parameters (flow rate and column oven temperature). To study the effect of flow rate on the resolution, the flow rate of mobile phase was altered by $\pm 0.2 \mathrm{ml} /$ minute $(1.8-2.2 \mathrm{ml}$ minute from $2.0 \mathrm{ml} /$ minute). The effect of column oven temperature on resolution was studied at $195^{\circ} \mathrm{C}$ and $200^{\circ} \mathrm{C}$ instead of $205^{\circ} \mathrm{C}$. The RSD (\%) obtained after changing the retention time and peak area was calculated, it should be not more than $10 \%$. In conclusion, variations in all the studied parameters had no significant effects on retention time or peak area, and the developed method proved to be robust for 2-CMP, 1, 4-DBB and PAA quantifications. The data of robustness is following Table 8.

\section{CONCLUSION}

A GC-MS at SIM mode method was developed and validated that allows a simple and accurate quantification of 2-CMP, 1,4-DBB and PAA simultaneously at a very low concentration levels. It is a simple, selective and sensitive method using inexpensive reagents. The Precision, Linearity, Accuracy, LOD and LOQ values were observed to be well within the set of acceptance criteria. The described method is highly reliable technique for the quantification of genotoxic impurities in the Mebeverine HCl. This method is useful in Pharmaceutical industries and formulation analysis.

\section{ACKNOWLEDGMENT}

The authors would like to thank the whole staff of Chemistry department of SVRM College for their technical support and productive discussions.

\section{REFERENCES}

1. Ramadevi, Srikanth S, Kumar AA. RP-HPLC method development and validation for simultaneous quantitative estimation of mebeverine 
$\mathrm{HCl}$ and chlordiazepoxide in capsules. Int J Pharm Pharm Sci 2014;7(2):314-8

2. Reddy PR, Reddy VK, Goud ES, Reddy YR. Development and validation of a ultra performance liquid chromatographic method for assay of mebeverine HCl. Int J Pharm Pharm Sci 2014;6 Suppl 2:442-5.

3. Kakasaheb NA, Ramakrishna K, Srinivasarao V. Method determination and validation of genotoxic impurities methyl methane soulfonate and methyl iodide in montelukast sodium drug substance by GC-MS. World J Pharm Res 2014;3(8):557-67.

4. Maddala VL, Ray PC, Venugopal K, Rao KM. A sensitive and selective GC-MS analysis of process related genotoxic impurities of nebivolol hydrochloride. Asian J Chem 2016;28(4):811-3.

5. Sarat M, Ramakrishna M, Suresh Y, Harikrishna S, Rambabu C, Kishore K, et al. Low-level determination of residual methyl methane sulfonate and ethyl methane sulfonate in pharmaceuticals by gas chromatography with mass spectrometry. E J Chem 2010;7(2):629-35.
6. Veenaeesh P, Manikumar G, Manjusha P, Padmasri A. Determination of methyl methane sulfonate, ethyl methane sulfonate and isopropyl methane sulfonate impurities in lopinavir API by GC/MS/MS using electron ionization. Int J Pharm Res Rev 2014;3(2):11-6.

7. ICH. Guidelines Q2B Validation of Analytical Procedures Methodology in Proceedings of International Conference on Harmonization. Rockville, USA; 1996. p. 1-10.

8. Belal TS, Mahrous MS, Abdel-Khalek MM, Daabees HG, Khamis MM. Validated HPTLC method for the simultaneous determination of alfuzosin, terazosin, prazosin, doxazosin and finasteride in pharmaceutical formulations. Anal Chem Res 2014;1:23-31.

9. Sriboonvorakul N, Leepipatpiboon N, Dondorp AM, Pouplin T, White NJ, Tarning J, et al. Liquid chromatographic-mass spectrometric method for simultaneous determination of small organic acids potentially contributing to acidosis in severe malaria. J Chromatogr B Analyt Technol Biomed Life Sci 2013;941:116-22. 